\title{
Long-term durability of pericardial valves in the aortic position in younger patients: when does reoperation become necessary?
}

\section{$\operatorname{AUTHOR}(S)$ :}

Minakata, Kenji; Tanaka, Shiro; Takahara, Yoshiharu; Kaneko, Tatsuo; Usui, Akihiko; Shimamoto, Mitsuomi; Okawa, Yohei; ... Yamanaka, Kazuo; Tamura, Nobushige; Sakata, Ryuzo

\section{CITATION:}

Minakata, Kenji ... [et al]. Long-term durability of pericardial valves in the aortic position in younger patients: when does reoperation become necessary?. Journal of cardiac surgery 2015, 30(5): 405-413

\section{ISSUE DATE:}

2015-03-19

\section{URL:}

http://hdl.handle.net/2433/200705

\section{RIGHT:}

This is the peer reviewed version of the following article: Minakata, K., Tanaka, S., Takahara, Y., Kaneko, T., Usui, A., Shimamoto, M., Okawa, Y., Yaku, H., Yamanaka, K., Tamura, N. and Sakata, R. (2015), Long-Term Durability of Pericardial Valves in the Aortic Position in Younger Patients: When Does Reoperation Become Necessary?. Journal of Cardiac Surgery, 30: 405-413, which has been published in final form at http://dx.doi.org/10.1111/jocs.12537. This article may be used for non-commercial purposes in accordance with Wiley Terms and Conditions for Self-Archiving. The full-text file will be made open to the public on 19 MAR 2016 in accordance with publisher's 'Terms and Conditions for SelfArchiving.:; This is not the published version. Please cite only the published version.; この論文は出版社版でありません 。引用の際には出版社版をご確認ご利用ください。 


\section{ORIGINAL ARTICLE}

\section{TITLE}

Long-term Durability of Pericardial Valves in the Aortic Position in Younger Patients: When does Reoperation Become Necessary?

SHORT RUNNING TITLE: Bioprosthesis in younger patients

Kenji Minakata, $\mathrm{MD}, \mathrm{PhD}^{\mathrm{a}}$

Shiro Tanaka, $\mathrm{PhD}^{\mathrm{b}}$

Yoshiharu Takahara, MD, $\mathrm{PhD}^{\mathrm{c}}$

Tatsuo Kaneko, MD, $\mathrm{PhD}^{\mathrm{d}}$

Akihiko Usui, $\mathrm{MD}, \mathrm{PhD}^{\mathrm{e}}$

Mitsuomi Shimamoto, $\mathrm{MD}, \mathrm{PhD}^{\mathrm{f}}$

Yohei Okawa, MD, $\mathrm{PhD}^{\mathrm{g}}$

Hitoshi Yaku, MD, $\mathrm{PhD}^{\mathrm{h}}$

Kazuo Yamanaka, MD, $\mathrm{PhD}^{\mathrm{i}}$

Nobushige Tamura, MD, $\mathrm{PhD}^{\mathrm{j}}$

Ryuzo Sakata, MD, $\mathrm{PhD}^{\mathrm{a}}$

\section{Affiliations:}

a. Department of Cardiovascular Surgery, Kyoto University Graduate School of Medicine

b. Department of Pharmacoepidemiology, Kyoto University Graduate School of Medicine and Public Health

c. Department of Cardiovascular Surgery, Funabashi Municipal Medical Center

d. Division of Cardiovascular Surgery, Gunma Prefectural Cardiovascular Center

e. Department of Cardiac Surgery, Nagoya University Graduate School of Medicine

f. Division of Cardiovascular Surgery, Shizuoka City Shizuoka Hospital

g. Division of Cardiovascular Surgery, Cardiovascular Center Hokkaido Ohno Hospital

h. Department of Cardiovascular Surgery, Kyoto Prefectural University of Medicine

i. Department of Cardiovascular Surgery, Tenri Hospital

j. Division of Cardiovascular Surgery, Kumamoto Central Hospital

Key words: Heart valve surgery, Aortic valve replacement, bioprosthesis, durability 
Total word count: 4,000; Number of tables: 4; Number of figures: 3

\section{Corresponding author:}

Kenji Minakata, Department of Cardiovascular Surgery, Kyoto University Graduate School of Medicine, 54 Kawahara-cho, Shogoin, Sakyo-ku, Kyoto, 606-8507, Japan

Phone: +81-75-751-3780

Fax: +81-75-751-3098

Email:minakata@kuhp.kyoto-u.ac.jp

\section{SOURCE OF FUNDING}

This work was supported by an educational grant from the Research Institute for Production Development (Kyoto, Japan).

\section{PPRESENTATION}

This paper was presented at the $60^{\text {th }}$ Annual Meeting of the Southern Thoracic Surgical Association, on November 1, 2013, in Scottsdale, Arizona, USA 


\section{Abstract (249 words)}

Background: There are a lack of data regarding the actual durability of bioprosthetic valves in younger patients. We sought to assess the long-term durability of pericardial valves in patients at age $<65$ years undergoing aortic valve replacement (AVR), and to determine the timing of redo operations due to structural valve deterioration (SVD).

Methods: From 1986 to 2001, a total of 574 adult patients underwent AVR with pericardial valves in 9 hospitals in Japan. Of these, 53 patients were at age $<65$ years (group Y). These patients were compared with those of age $\geq 65$ (group O, n=521).

Results: The mean follow-up duration was 9.5 years in group Y and 8.1 years in group O. Freedom from reoperation due to SVD was $100 \%$ at 5 years, $90.8 \%$ at 10 years, and $47.2 \%$ at 15 years in group $\mathrm{Y}$, and $99.3 \%$ at 5 years, $97.4 \%$ at 10 years, and $94.4 \%$ at 15 years in group $\mathrm{O}$ (log-rank test, $\mathrm{p}<0.01$ ). In those who required redo AVR in group $Y(n=12)$, the mean time from initial operation to reoperation was 12.1 years. The reoperation-free survival curve started to decline after 8 years postoperation in group $\mathrm{Y}$.

Conclusions: Redo AVR started to become necessary 8 years after surgery in the patients who underwent AVR with pericardial valve at age $<65$ years. In addition, approximately a half of those 
patients had required reoperation due to SVD by 15 years postoperatively. Some of these patients can be good candidates for the up-coming technology of the transcatheter intervention.

\section{INTRODUCTION}

The Society of Thoracic Surgeons (STS) recently published clinical practice guidelines for the treatment of aortic valves in 2013 [1]. According to the guidelines, a bioprosthesis is recommended for aortic valve replacement (AVR) in patients age 65 years or older without risk factors for thromboembolism. This consensus itself was first described in the American College of Cardiology (ACC)/American Heart Association (AHA) treatment guidelines for valvular heart disease patients published in 2006 [2]. These guidelines reflect a significant trend towards tissue valves in elderly patients requiring AVR. In fact, the excellent durability of tissue valves, particularly in elderly patients, has been well described in many reports published over the last two decades [3-8]. On the other hand, a bioprosthesis may be reasonable for AVR in patients at age less than 65 years who choose this valve based on lifestyle considerations after detailed discussions. This recommendation for patients aged less than 65 years was defined as Class IIa by the 2006 ACC/AHA guidelines, whereas this is downgraded, and defined as Class IIb by the 2013 STS guidelines. Also, the most recent ACC/AHA guidelines, which was revised in 2014, defines that a bioprosthesis is reasonable 
in patients more than 70 years of age (class IIa recommendation) [9]. These discrepancies may be related to the fact that there are very few data regarding the actual durability of pericardial valves and long-term survival in younger patients aged less than 65 or 70 years. We recently published the overall results of a Japanese multi-center study to evaluate the long-term durability of pericardial valves in aortic position [10]. Thus, the aim of this sub-study analysis was to assess the long-term durability of pericardial valves in patients undergoing AVR at age less than 65 years, and to determine the timing of redo operation due to structural valve deterioration (SVD).

\section{MATERIALS and METHODS}

We enrolled all patients who underwent AVR with the Carpentier-Edwards PERIMOUNT pericardial (CEP) bioprosthesis (Edwards Lifesciences, Irvine, CA, USA) from January 1986 to December 2001 in the participating 9 hospitals. There were very few types of bioprosthesis available in Japan during the study periods. In fact, CEP was the only bioprosthesis used in the aortic position in all the study sites. Also, mechanical valves were predominantly used in 1980's and 1990's. The reason we did not included the patients who underwent AVR with CEP after 2002 was primarily due to the aim of longterm follow-up over 10 years in this study focusing on the durability of this bioprosthesis. The details of the study were described elsewhere [10]. In short, the total number of patients enrolled was 591. 
Of these, 574 patients were eligible for this study (17 patients were ineligible due to refusal or lack of informed consent). Of note, in addition to the patients who underwent aortic root replacement with composite grafts using CEP bioprosthesis, those who underwent concomitant procedures such as coronary artery bypass grafting (CABG), mitral or tricuspid valves repair or replacement, and aortic aneurysm repair were also included. Of the 574 patients, 53 patients were age less than 65 years at the time of operation (group Y). This group of patients was compared to the other group of patients who were 65 years of age or older at the time of operation (group O) in this study.

All the patients' characteristics and operative data were obtained from medical records at each participating hospitals by independent clinical research coordinators according to pre-specified criteria. In addition, all of the patients who survived the operation underwent follow-up surveys. Late outcomes were determined from medical records when available, from written correspondence with patients' physicians, or direct patient contact via mailed questionnaires or telephone interviews when necessary. Clinical data at the latest follow-up were collected by contacting referring physicians. The follow-up survey was closed in December 2012. This study was approved by the Institutional Review Board at all the participating hospitals and the Ethics Committee of the Kyoto University Graduate School and Faculty of Medicine. All patients or their family members gave informed consent. 
The patients' baseline characteristics and operative variables in each group are shown in Table 1. In terms of the aortic valve pathology, bicuspid aortic valve was relatively more common in group Y. Also, active endocarditis was more common in group Y. On the other hand, calcified tricuspid aortic valves were more common in group $\mathrm{O}$. Patients in group $\mathrm{O}$ tended to undergo more concomitant procedures including CABG and aortic aneurysm repair, whereas mitral valve procedures were more commonly performed in group $\mathrm{Y}$, although there were no statistical differences. In terms of the reasons of valve selection, the bioprosthesis was chosen most likely due to high age in group $\mathrm{O}$. The indications of the bioprosthesis in group Y included desire for child bearing, relatively high age ( $\geq$ 60 years), limited life expectancy, prior mechanical valve failure, and so on. In particular, there were 10 patients who were on atrial fibrillation preoperatively in group Y. Of those, the indication of the use of bioprosthesis included relatively high age in 6 , desire for child bearing in 2, and prior mechanical valve failure in 2 .

\section{Definitions of Events and Statistical Analysis}

Definitions of SVD and other valve-related events such as thromboembolism or bleeding events were based on the STS guidelines for reporting mortality and morbidity after cardiac valve interventions 
[11]. In short, the term structural valve deterioration refers to changes intrinsic to the valve, such as wear, fracture, poppet escape, calcification, leaflet tear, stent creep, and suture line disruption of components of a prosthetic valve. Nonstructural dysfunction refers to any abnormality not intrinsic to the valve itself that resulted in stenosis or regurgitation of the operated valve or hemolysis. Nonstructural dysfunction includes entrapment by pannus, tissue, or suture; paravalvular leakage; inappropriate sizing or positioning; residual leakage or obstruction after valve implantation or repair; and clinically important intravascular hemolytic anemia. Valve-related death was defined as any death caused by structural valve deterioration, nonstructural dysfunction, valve thrombosis, embolism, bleeding event, or operated valve endocarditis; death related to reintervention on the operated valve; or sudden, unexplained death. In-hospital mortality was defined as death occurring within 30 days of surgery or at any time during the index hospitalization.

Postoperative overall survival, freedom from valve-related death, valve-related events, and reoperation due to SVD were estimated by the Kaplan-Meier method. The associations of potential risk factors to survival and events were assessed with log-rank tests. All continuous variables were expressed as mean \pm standard deviation. All p-values are two-sided and a p-value $<0.05$ was considered statistically significant. All data analysis was carried out by an academic statistician (S.T.) 
using SAS software version 9.2 (SAS Institute Inc., Cary, NC, USA).

\section{RESULTS}

As shown in Table 2, there were 2 (3.8\%) in-hospital deaths in group Y, and 24 (4.6\%) in group O $(p=0.78)$. The overall mean and median follow-up duration were 8.2 and 9.2 years, respectively. The rate of overall follow-up completeness was $83.1 \%$. Reoperation of the aortic valve prosthesis was necessary in 12 patients in group $\mathrm{Y}$, and 12 patients in group $\mathrm{O}$. Of note, only 6 patients out of 12 who required redo operation in group O actually had SVD as a primary indication. In fact, in group $\mathrm{O}$, the other indication for redo AVR included prosthetic valve endocarditis (PVE) in 4 patients, and paravalvular leak in one. One patient underwent redo AVR at the time of a mitral valve replacement, which was the primary indication of the surgery. In-hospital mortality of redo operations in group Y was $8.3 \%(n=1)$, whereas it was $16.7 \%(n=2)$ in group O. When the patients who required redo AVR because of PVE were excluded, the in-hospital mortality was 5.6\% overall (8.3\% in group Y and 0\% in group $\mathrm{O})$. The mean duration from the initial operation to the overall redo operation was $12.1+4.3$ years in group $\mathrm{Y}$ and $7.7+3.9$ years in group $\mathrm{O}(\mathrm{p}=0.013)$. Of note, in group $\mathrm{O}$, the mean duration from the initial operation to the redo operation due to SVD was 9.4+3.3 years. The detailed information of each patient who required a redo operation is given in Table 3. 
Survival curves estimated by the Kaplan-Meier method are shown in Figure 1. Although freedom

from all-cause death was higher in group $\mathrm{Y}$ (log-rank $\mathrm{p}<0.01$ ), there was no statistical difference in freedom from valve-related death between groups $(\log -r a n k p=0.45)$. In addition, there were no statistical differences between groups in terms of freedom from thromboembolic events and major bleeding events (Figure 2). As shown in Figure 3 (left), freedom from reoperation due to SVD was $100 \%$ in 5 years, $90.8 \%$ in 10 years, and $47.2 \%$ in 15 years in group $Y$, while it was $99.3 \%$ in 5 years, $97.4 \%$ in 10 years, and $94.4 \%$ in 15 years in group O (log-rank $\mathrm{p}<0.01)$. In group $\mathrm{Y}$, the reoperationfree curve suddenly starts to decline at approximately 8 years post-operation, and more than half of the patients in group Y had undergone redo AVR by 15 years post-operation. Also, freedom from reoperation due to SVD stratified according to the age at operation is demonstrated in Figure 3 (right).

\section{DISCUSSION}

It is obvious that SVD is inevitable for all tissue valves over time and reoperation becomes necessary at some point, however, many elderly patients die before the degree of SVD reaches the point where reoperation is indicated. This is one of the reasons why elderly patients benefit most from selecting tissue valves over mechanical valves, which require life-long anticoagulation therapy. However, it 
remains unclear when reoperation becomes necessary in younger patients who undergo AVR with tissue valves. In the current study, we demonstrated that in patients aged younger than 65 years who underwent AVR with a CEP bioprosthesis, reoperation due to SVD started to become necessary after 8 years. In these patients requiring reoperation, the mean duration from the initial operation to reoperation was approximately 12 years. Also, more than $50 \%$ of the patients required reoperation due to SVD within 15 years postoperatively.

As an alternative to a pericardial valve, a porcine valve has been the bioprosthesis of choice for years. The long-term durability of porcine valves has also been reported to be excellent. David et al. reported that freedom from reoperation due to SVD at 20 years in patients who had undergone AVR with Hancock II porcine bioprosthetic valves at ages $60-70$, and $\geq 70$ were $85.2 \%$ and $99.8 \%$, respectively [12]. There have been very few direct comparisons of the long-term durability between porcine and pericardial valves, especially in younger patients [13]. There are a few reports, however, regarding the durability of porcine valves in younger patients. Jamieson et al. reported that rates of porcine valve failure at 15 years postoperatively are $46 \%$ for patients in their fifth decade of life and $42 \%$ for patients in their sixth decade [14]. Likewise, Fann et al. reported that rates of SVD in porcine valves after 15 years were 53\% in the fifth decade of life, and 56\% in the sixth decade of life [15]. Our results 
seem to be consistent with those of both aforementioned studies. Therefore, our data support the consensus that there are no major differences in terms of the durability between current porcine and pericardial valves $[16,17]$. Also, there were no survival differences between patients receiving porcine valves and patients receiving pericardial valves [18]. In general, the incidence of requiring reoperation due to SVD becomes higher when patients are younger [3, 7, 14-17]. In fact, Une et al. reported that freedom from reoperation due to SVD in patients receiving porcine bioprosthesis at 20 years were $41 \%, 21 \%$, and $14 \%$ in the fifth, fourth, and less than third decade of life , respectively [18]. It is unknown why the durability is inferior in younger patients. Although it remains anecdotal, one can speculate that the pathological process of SVD may be related to the sum of mechanical stresses with opening and closing from possible higher heart rates due to more active physical activities, and/or metabolic factors involving higher level of calcium metabolisms in younger populations that cause leaflet calcification.

There are certain clinical settings where the use of bioprosthesis is mandatory in younger patients who have contraindications to warfarin. In fact, a bioprosthesis may be indicated in young women who wish to bear a child because of the teratogenicity of warfarin [1, 2]. In the current study, 9 patients less than 40 years of age who desired to bear children underwent AVR with a CEP bioprosthesis. Of 
these, 6 patients required reoperation due to SVD after a mean at 12.4 years (ranged 7.4 to 23.9 years)

postoperatively with no in-hospital mortality. Based on our data, it seems reasonable to use a CEP bioprosthesis in such younger female patients, given the fact that a CEP bioprosthesis gives at least a 7-year window period during which anticoagulation is unnecessary.

In terms of long-term survival after tissue AVR, the overall survival rate at 15 years was $53.5 \%$ in the younger group. Jamieson et al. reported that 15-year survival after AVR with porcine bioprosthesis at age 51-60 was 46.4\% [14], also Suri et al. reported that 15-year survival after tissue AVR at age between 40-59 years was 55.0\% [20], both of which had similar outcomes to our results. It remains unknown why tissue AVR provides poor long-term survival in younger patients. There may have been selection bias which did not appear on data. One can speculate that bioprosthetic valves had been chosen instead of mechanical prosthesis for some reasons such as possible limited life expectancy or poor compliance in those younger patients. On the other hand, there has been a growing body of literature, which may indicate the survival benefit using mechanical prosthesis over bioprostheis in younger patients undergoing AVR [20-22].

According to the recent STS guidelines [1], a bioprosthesis is recommended for AVR in patients aged 
65 years or more without risk factors for thromboembolism. This recommendation is Class I. Also, the European Society's guidelines describe that a bioprosthesis is recommended according to the desire of the informed patient regardless of the age, which is defined as Class I recommendation [23]. Our durability data of pericardial valves stratified according to the age at operation demonstrated that patients age $\geq 70$ years had almost no chance of reoperation due to SVD (figure 3, right). However, some of the patients between 65 and 69 years required reoperation due to SVD after approximately 8 years up to 12 years, just like the younger patients at age $<65$ years. Therefore, patients at age between 65 and 69 years, in addition to the younger patients at age $<65$ years, should also be given the information regarding the highly potential need for reoperation due to SVD. In other words, patients at age 65 and 69 years may have benefit of higher freedom from reoperation by choosing mechanical valves. This finding may support the reasonable indication of the bioprostheses in patients age 70 years or older, described in the 2014 ACC/AHA guidelines [9].

As shown in Table 3, various types of concomitant procedures may be necessary at the time of redo AVR. Especially in patients with a bicuspid aortic valve, replacement of the ascending aorta is often indicated concomitantly due to aneurysmal dilatation of the ascending aorta, even when aneurysm repair was not indicated at the initial operation. It is well known that patients with a bicuspid aortic 
valve have a higher tendency to develop aneurysmal dilatation of the aorta in addition to aortic valve diseases [1]. According to the STS guidelines, the indication for surgical repair of the ascending aorta is a diameter of $5.0 \mathrm{~cm}$ and more in patients with a bicuspid aortic valve, whereas it is $5.5 \mathrm{~cm}$ otherwise [1]. Close follow-up with diagnostic imaging such as CT scan is mandatory in patients with aortic valve disease, particularly for those with a bicuspid aortic valve.

Recently, an emerging technology known as transcatheter aortic valve replacement (TAVR) has become available in patients with severe symptomatic aortic stenosis (AS) who are considered to be inoperable or have higher risk for surgical mortality [24]. Although TAVR is currently approved only for patients with native valve severe AS, this technology can be applied to those who have failed tissue valves [25]. In fact, a relatively large registry data of TAVR in failed bioprosthetic valves was recently published [26]. Although preoperative conditions such as diameter of the aortic annulus, vascular access and co-morbidity need to be evaluated in each patient, some of the patients with failed bioprosthesis can certainly be excellent candidates for TAVR. It is also expected that newer devices with more advanced technology for a wider range of prostheses and a more flexible delivery system can resolve many of the current technical limitations in the near future. Yet, the current theoretical feasibility of TAVR in our series of patients who had failed CEP bioprosthesis is not well defined. It 
is true that the small internal diameter of the prosthesis, especially $19 \mathrm{~mm}$ valve, may preclude a candidacy of current valve-in-valve TAVR. Indeed, a small size of the failed bioprosthesis less than 21mm carried higher short-term and mid-term mortality [26]. Also, those who had prosthetic valve infection and paravalvular leakage or concomitant other valvular and/or aortic lesions may not be good candidates for valve-in-valve TAVR. Our data certainly suggest that the younger patients who had failed tissue valves due to SVD can more likely be candidates for TAVR. It remains unknown, however, this valve-in-valve technology would change the indication of bioprosthesis because there have been no long-term follow-up data in patients undergoing TAVR.

\section{Limitations}

There were several limitations in this study. First, this was a retrospective, non-randomized study.

Also, many of the patients died several years prior to the study, and events occurred years before the study was performed, making it difficult to obtain accurate information, especially for valve-related events. Likewise, the follow-up completeness was somewhat low at $83.1 \%$ with 10 -year follow-up completeness of $82.6 \%$. These factors may have influenced the results significantly. Also, freedom from reoperation due to SVD does not mean the real freedom from SVD itself, although it is unlikely that reoperation is refused by younger patients if indicated. 


\section{CONCLUSIONS}

In patients who underwent AVR with CEP bioprosthesis at age $<65$ years, redo AVR due to SVD started to become necessary after 8 years postoperatively, and approximately a half of the patients underwent redo AVR due to SVD by 15 years. Some of these patients can be good candidates for the up-coming technology of the transcatheter intervention.

\section{Acknowledgements}

We are indebted to the participating hospitals, investigators, and clinical research coordinators for their great contributions to data collection. Participating hospitals: Cardiovascular Center Hokkaido Ohno Hospital (Sapporo), Gunma Cardiovascular Center (Maebashi), Funabashi Municipal Medical Center (Funabashi), Shizuoka City Shizuoka Hospital (Shizuoka), Nagoya University Hospital (Nagoya), Tenri Hospital (Tenri), University Hospital, Kyoto Prefectural University of Medicine (Kyoto), Kyoto University Hospital (Kyoto), and Kumamoto Central Hospital (Kumamoto).

\section{Conflict of interest: none declared}

\section{Figure legends}

Figure 1. Freedom from all-cause death (left) and valve-related death (right) according to age groups

Figure 2. Freedom from thromboembolic events (left) and bleeding events (right) according to age groups 
Figure 3. Freedom from reoperation due to structural valve deterioration according to age groups

\section{Author contributions}

Kenji Minakata: concept, design of the study, drafting

Shiro Tanaka: statistics, data analysis

Yoshiharu Takahara: data collection and analysis/interpretation

Tatsuo Kaneko: data collection and analysis/interpretation

Akihiko Usui: data collection and analysis/interpretation

Mitsuomi Shimamoto: data collection and analysis/interpretation

Yohei Okawa: data collection and analysis/interpretation

Hitoshi Yaku: data collection and analysis/interpretation

Kazuo Yamanaka: data collection and analysis/interpretation

Nobushige Tamura: data collection and analysis/interpretation

Ryuzo Sakata: critical revision of the article

\section{REFERENCES}

1. Svensson LG, Adams DH, Bonow RO, et al: Aortic valve and ascending aorta guidelines or management and quality measures. Ann Thorac Surg 2013;95(6 Suppl):S1-66.

2. American College of Cardiology/American Heart Association Task Force on Practice Guidelines;

Society of Cardiovascular Anesthesiologists; Society for Cardiovascular Angiography and Interventions; Society of Thoracic Surgeons; Bonow RO, Carabello BA, Kanu C, et al. ACC/AHA 2006 guidelines for the management of patients with valvular heart disease: a report of the American College of Cardiology/American Heart Association Task Force on Practice 
Guidelines (writing committee to revise the 1998 Guidelines for the Management of Patients With Valvular Heart Disease): developed in collaboration with the Society of Cardiovascular Anesthesiologists: endorsed by the Society for Cardiovascular Angiography and Interventions and the Society of Thoracic Surgeons. Circulation 2006;114:e84-231.

3. Forcillo J, Pellerin M, Perrault LP, et al: Carpentier-Edwards pericardial valve in the aortic position: 25-years experience. Ann Thorac Surg 2013;96:486-93.

4. McClure RS, Narayanasamy N, Wiegerinck E, et al: Late outcomes for aortic valve replacement with the Carpentier-Edwards pericardial bioprosthesis: up to 17-year follow-up in 1,000 patients. Ann Thorac Surg 2010;89:1410-1416.

5. Banbury MK, Cosgrove DM 3rd, White JA, et al: Age and valve size effect on the long-term durability of the Carpentier-Edwards aortic pericardial bioprosthesis. Ann Thorac Surg 2001;72: 753-757.

6. Poirer NC, Pelletier LC, Pellerin M, et al: 15-year experience with the Carpentier-Edwards pericardial bioprosthesis. Ann Thorac Surg 1998;66(6 Suppl):S57-61.

7. Aupart MR, Mirza A, Meurisse YA, et al: Perimount pericardial bioprosthesis for aortic calcified stenosis: 18-year experience with 1133 patients. J Heart Valve Dis 2006;15:768-775. 
8. Nishida T, Tominaga R: A look at recent improvements in the durability of tissue valves. Gen Thorac Cardiovasc Surg 2013;61:182-190.

9. Nishimura RA, Otto CM, Bonow RO, et al; American College of Cardiology/American Heart Association Task Force on Practice Guidelines. 2014 AHA/ACC guideline for the management of patients with valvular heart disease: executive summary: a report of the American College of Cardiology/American Heart Association Task Force on Practice Guidelines. J Am Coll Cardiol 2014; 63:2438-88.

10. Minakata K, Tanaka S, Okawa Y, et al: Long-term Outcomes of the Carpentier-Edwards Pericardial Valve in the Aortic Position in Japanese Patients. Circ J 2014;78:882-889.

11. Akins CW, Miller DC, Turina MI, et al: Guidelines for reporting mortality and morbidity after cardiac valve interventions. Ann Thorac Surg 2008;85:1490-1495.

12. David TE, Armstrong S, Maganti M. Hancock II. Bioprosthesis for aortic valve replacement: the gold standard of bioprosthetic valves durability? Ann Thorac Surg 2010; 90: 775-781.

13. Gao G, Wu Y, Grunkemeier GL, et al: Durability of pericardial versus porcine aortic valves. J Am Coll Cardiol 2004;44:384-388.

14. Jamieson WR, Ling H, Burr LH, et al: Carpentier-Edwards supraannular porcine bioprosthesis evaluation over 15 years. Ann Thorac Surg 1998;66(6 Suppl):S49-52. 
15. Fann JI, Miller DC, Moore KA, et al: Twenty-year clinical experience with porcine bioprostheses. Ann Thorac Surg 1996;62:1301-1311.

16. Chikwe J, Filsoufi F: Durability of tissue valves. Semin Thorac Cardiovasc Surg 2011;23:18-23.

17. Nishida T, Tominaga R: A look at recent improvements in the durability of tissue valves. Gen Thorac Cardiovasc Surg 2013;61:182-190.

18. Said SM, Ashikhmina E, Greason KL, et al. Do pericardial bioprostheses improve outcome of elderly patients undergoing aortic valve replacement? Ann Thorac Surg 2012; 93: 1868-1874.

19. Une D, Ruel M, David TE. Twenty-year durability of the aortic Hancock II bioprosthesis in young patients: is it durable enough? Eur J Cardiothorac Surg 2014;46:825-30.

20. Suri RM, Schaff HV: Is tissue valve the preferred option for patients aged 60 years and older? Circulation 2013;128:1372-1380.

21. Hammermeister K, Sethi GK, Henderson WG, et al: Outcomes 15 years after valve replacement with a mechanical versus a bioprosthetic valve: final report of the Veterans Affairs randomized trial. J Am Coll Cardiol 2000;36:1152-1158.

22. Weber A, Noureddine H, Englberger L, et al. Ten-year comparison of pericardial tissue valves versus mechanical prostheses for aortic valve replacement in patients younger than 60 years of age. J Thorac Cardiovasc Surg 2012;144:1075-1083. 
23. Vahanian A, Alfieri O, Andreotti F, et al; ESC Committee for Practice Guidelines (CPG); Joint Task Force on the Management of Valvular Heart Disease of the European Society of Cardiology (ESC); European Association for Cardio-Thoracic Surgery (EACTS): Guidelines on the management of valvular heart disease (version 2012): the Joint Task Force on the Management of Valvular Heart Disease of the European Society of Cardiology (ESC) and the European Association for Cardio-Thoracic Surgery (EACTS). Eur J Cardiothorac Surg 2012;42:S1-44.

24. Smith CR, Leon MB, Mack MJ, et al: Transcatheter versus surgical aortic-valve replacement in high-risk patients. N Engl J Med 2011;364:2187-2198.

25. Walther T, Falk V, Dewey T, et al: Valve-in-a-valve concept for transcatheter minimally invasive repeat xenograft implantation. J Am Coll Cardiol 2007;50:56-60.

26. Dvir D, Webb JG, Bleiziffer S, et al: Transcatheter aortic valve implantation in failed bioprosthetic surgical valves. JAMA 2014;312:162-70 


\section{Figure 1}
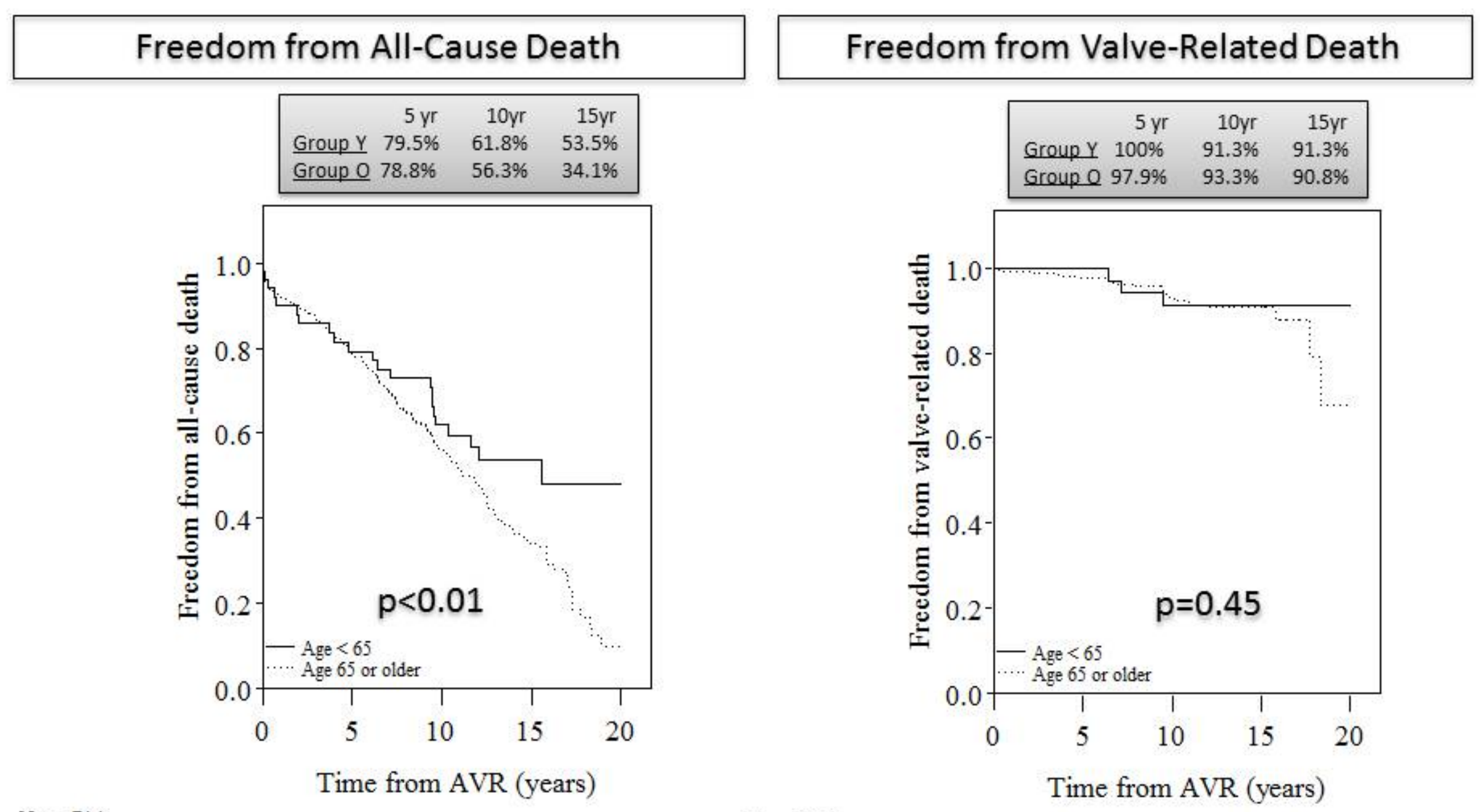

$\begin{array}{ccccc}53 & 37 & 27 & 10 & 2 \\ 520 & 348 & 231 & 44 & 2\end{array}$

$\begin{array}{cc}37 & 27 \\ 348 & 231\end{array}$

$\begin{array}{ll}10 & 2 \\ 44 & 2\end{array}$




\section{Figure 2}

\section{Freedom from Thromboembolic Events}

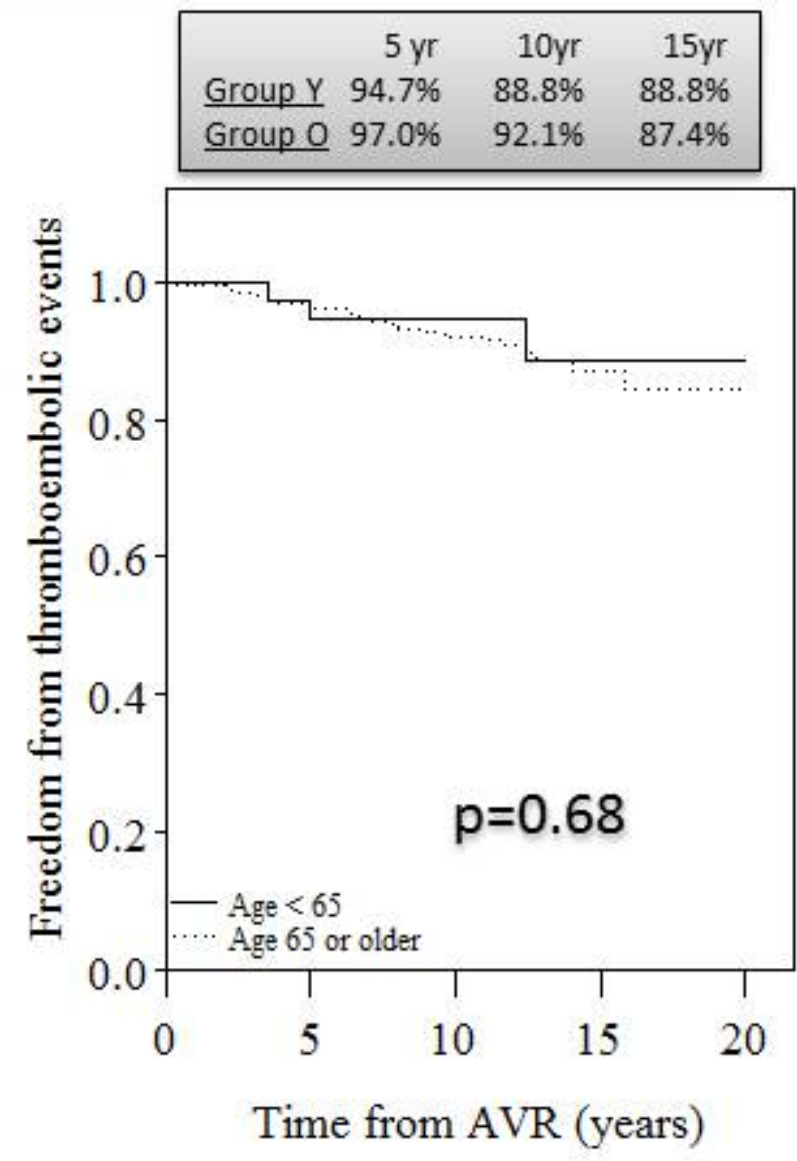

No. at Risk

$\begin{array}{ccccc}47 & 35 & 27 & 9 & 2 \\ 457 & 334 & 225 & 41 & 2\end{array}$

\section{Freedom from Bleeding Events}

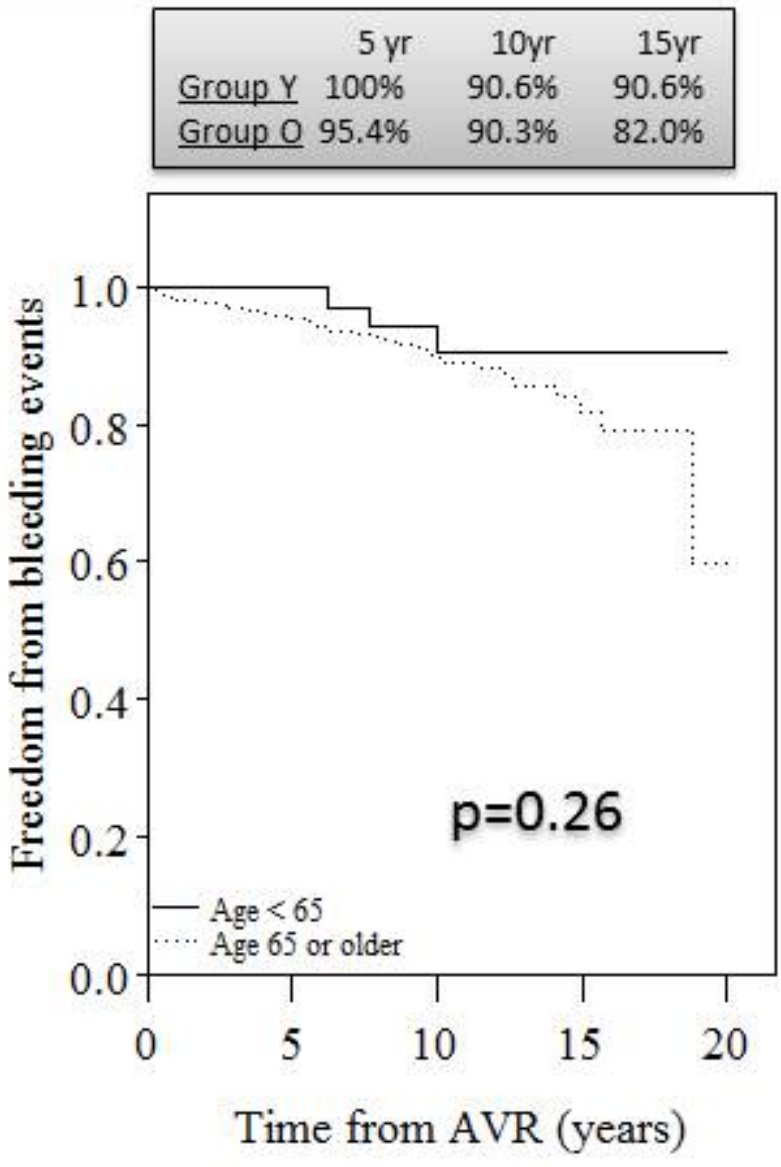

No. at Risk

Age 65 or older

$\begin{array}{ccccc}47 & 37 & 25 & 10 & 2 \\ 457 & 335 & 221 & 38 & 1\end{array}$




\section{Figure 3}

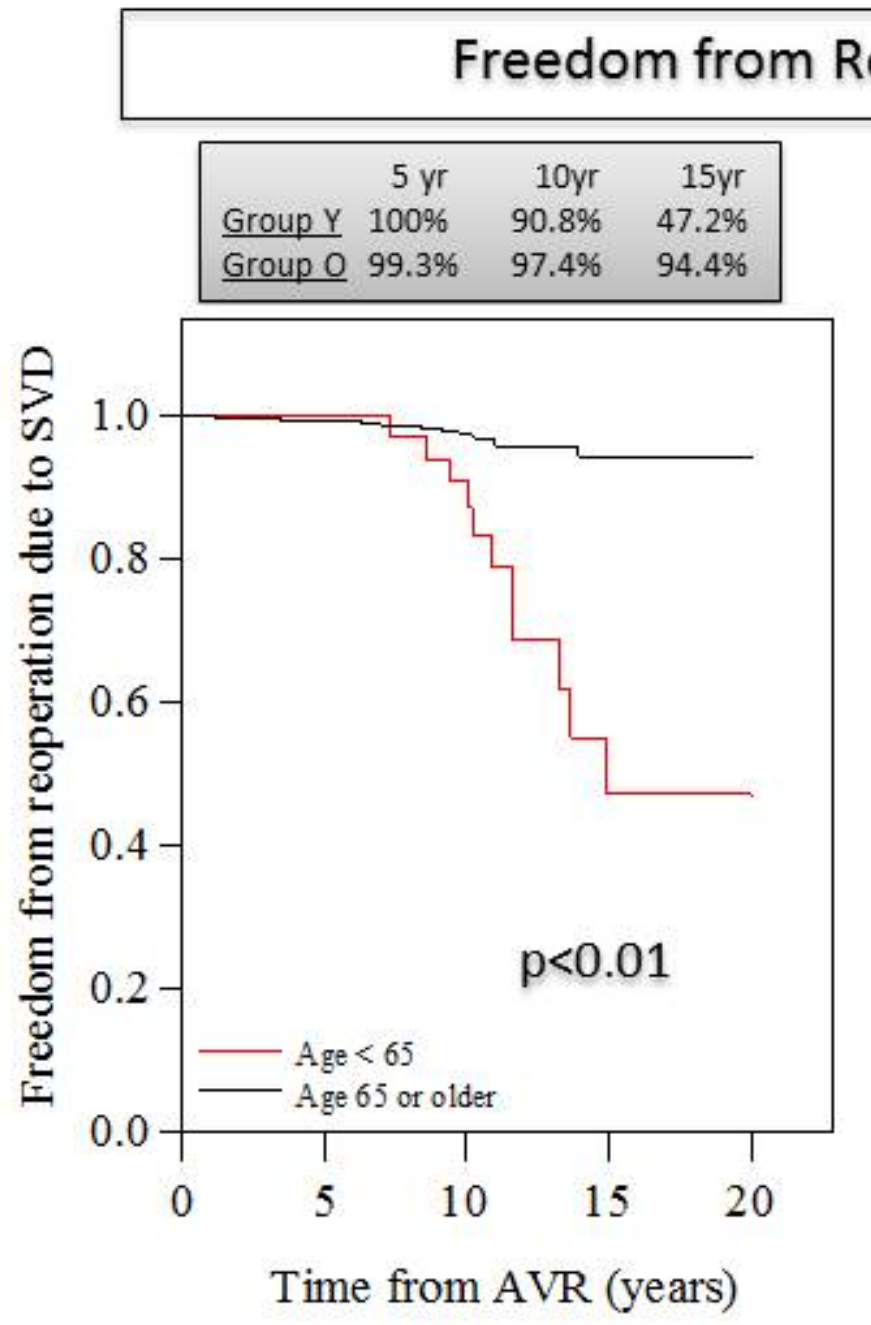

$\begin{array}{ccccc}47 & 37 & 25 & 6 & 1 \\ 457 & 340 & 226 & 41 & 1\end{array}$

No. at Risk

Age younger than 65 Age 65 to 69 Age 70 to 74 Age 75 to 79 Age 80 or older

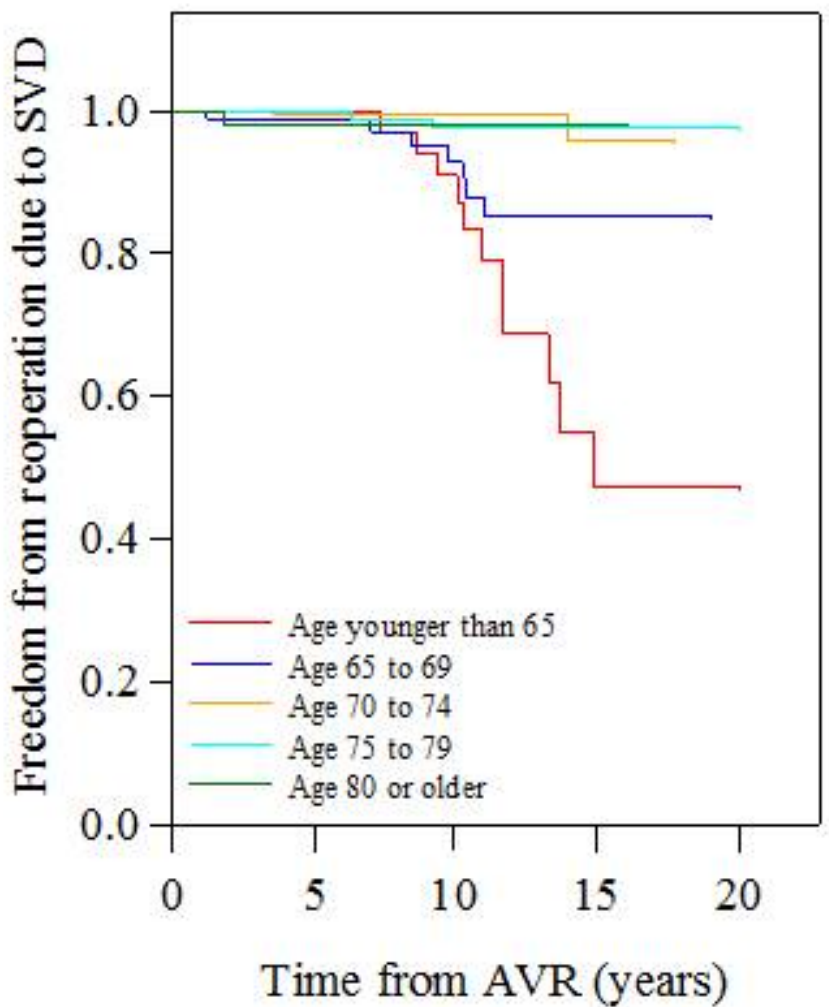

$\begin{array}{ccccc}47 & 37 & 25 & 6 & 1 \\ 79 & 60 & 41 & 8 & \\ 182 & 140 & 101 & 18 & \\ 140 & 105 & 69 & 13 & 1 \\ 56 & 35 & 15 & 2 & \end{array}$

